\title{
IMMUNEPOTENT CRP induces DAMPS release and ROS-dependent autophagosome formation in HeLa and MCF-7 cells
}

Ana Carolina Martínez-Torres ${ }^{1 *} \mathbb{D}$, Alejandra Reyes-Ruiz ${ }^{1 \dagger}$, Kenny Misael Calvillo-Rodriguez ${ }^{1 \dagger}$, Karla Maria Alvarez-Valadez ${ }^{1 \dagger}$, Ashanti C. Uscanga-Palomeque ${ }^{1}$, Reyes S. Tamez-Guerra ${ }^{1}$ and Cristina Rodríguez-Padilla ${ }^{1,2}$

\begin{abstract}
Background: IMMUNEPOTENT CRP (ICRP) can be cytotoxic to cancer cell lines. However, its widespread use in cancer patients has been limited by the absence of conclusive data on the molecular mechanism of its action. Here, we evaluated the mechanism of cell death induced by ICRP in HeLa and MCF-7 cells.

Methods: Cell death, cell cycle, mitochondrial membrane potential and ROS production were evaluated in HeLa and MCF-7 cell lines after ICRP treatment. Caspase-dependence and ROS-dependence were evaluated using QVD.oph and NAC pre-treatment in cell death analysis. DAMPs release, ER stress (elF2-a phosphorylation) and autophagosome formation were analyzed as well. Additionally, the role of autophagosomes in cell death induced by ICRP was evaluated using SP-1 pre-treatment in cell death in HeLa and MCF-7 cells.

Results: ICRP induces cell death, reaching $\mathrm{CC}_{50}$ at $1.25 \mathrm{U} / \mathrm{mL}$ and $1.5 \mathrm{U} / \mathrm{mL}$ in HeLa and MCF-7 cells, respectively. Loss of mitochondrial membrane potential, ROS production and cell cycle arrest were observed after ICRP CC $_{50}$ treatment in both cell lines, inducing the same mechanism, a type of cell death independent of caspases, relying on ROS production. Additionally, ICRP-induced cell death involves features of immunogenic cell death such as PeIF2a and CRT exposure, as well as, ATP and HMGB1 release. Furthermore, ICRP induces ROS-dependent autophagosome formation that acts as a pro-survival mechanism.
\end{abstract}

Conclusions: ICRP induces a non-apoptotic cell death that requires an oxidative stress to take place, involving mitochondrial damage, ROS-dependent autophagosome formation, ER stress and DAMPs' release. These data indicate that ICRP could work together with classic apoptotic inductors to attack cancer cells from different mechanisms, and that ICRP-induced cell death might activate an immune response against cancer cells.

Keywords: Autophagy, DAMPs, Bovine dialyzable leukocyte extract, ROS, Immunotherapy, Transfer factor

\footnotetext{
* Correspondence: ana.martinezto@uanl.edu.mx

${ }^{\dagger}$ Alejandra Reyes-Ruiz, Kenny Misael Calvillo-Rodriguez and Karla Maria Alvarez-Valadez contributed equally to this work.

${ }^{1}$ Universidad Autonoma de Nuevo Leon, Facultad de Ciencias Biologicas, Laboratorio de Inmunologia y Virologia, San Nicolás de los Garza, Mexico Full list of author information is available at the end of the article
}

C C The Author(s). 2020 Open Access This article is licensed under a Creative Commons Attribution 4.0 International License, which permits use, sharing, adaptation, distribution and reproduction in any medium or format, as long as you give appropriate credit to the original author(s) and the source, provide a link to the Creative Commons licence, and indicate if changes were made. The images or other third party material in this article are included in the article's Creative Commons licence, unless indicated otherwise in a credit line to the material. If material is not included in the article's Creative Commons licence and your intended use is not permitted by statutory regulation or exceeds the permitted use, you will need to obtain permission directly from the copyright holder. To view a copy of this licence, visit http://creativecommons.org/licenses/by/4.0/. The Creative Commons Public Domain Dedication waiver (http://creativecommons.org/publicdomain/zero/1.0/) applies to the data made available in this article, unless otherwise stated in a credit line to the data. 


\section{Background}

Among the different types of cancer, breast and cervical cancer remain the principal causes of women death worldwide [1]. Main treatments consist of surgical removal of the tumor, chemotherapy, radiation therapy, hormonal therapy, and immunotherapy. However, these treatments still have limited success, and the development of new therapies to improve existing ones is a major challenge.

IMMUNEPOTENT CRP (ICRP), a bovine dialyzable leukocyte extract (DLE) obtained from disintegrated spleen, is cytotoxic to several cancer cell lines, including those from lung cancer [2] cervical cancer [3] and breast cancer $[4,5]$, while sparing noncancerous cells [6]. In murine melanoma, it prevented cell growth and diminished VEGF release [7]. In the cervical cancer cell lines $\mathrm{HeLa}$ and $\mathrm{SiHa}$, and the non-small cell lung cancer cell lines A549, and A427, it induced cell cycle arrest and caspase-independent but ROS-dependent cell death [2, 3]. Additionally, its administration promoted a decrease in tumor volume and an increase in the survival of mice bearing $4 \mathrm{~T} 1$ tumors without visibly affecting vital organs, or hematological and biochemical parameters [8]. Additionally, ICRP induced immunogenic cell death (ICD) alone or in combination with oxaliplatin in the murine model B16F10 [9]; this immunogenicity of cancer cell death relies on the antigenicity of the neoantigens expressed by dead cancer cells and the release of damage-associated molecular patterns (DAMPs) such as calreticulin (CRT), ATP and HMGB1 [10]. Until today, every ICD inductor causes endoplasmic reticulum (ER) stress, which implies several cellular processes as eIF2 $\alpha$ phosphorylation (P-eIF $2 \alpha$ ) and exposure of chaperone proteins like CRT [11]. Besides ER stress, production of reactive oxygen species (ROS) is an essential component that instigates the intracellular danger-signalling pathways that govern ICD. ROS and other reactive species are the main intracellular signal transducers sustaining autophagy, thus, several studies have shown an autophagy-ROS dependence for the release of DAMPs [12, 13].

Autophagy is a primary survival mechanism activated in cells subjected to stress. However, if cellular stress continues, autophagy often becomes associated with features of cell death. This dual role of autophagy has been associated with the resistance of cancer cells to treatments (as a pro-survival process) or the induction of cell death (as a pro-death process) depending on the stimulus. Moreover, autophagy can be dispensable for the induction of cell death but required for its immunogenicity $[14,15]$.

The purpose of this study was to analyze the molecular pathways by which ICRP exerts its cytotoxicity. We used HeLa and MCF-7 cell lines to further characterize its mechanism of cytotoxicity evaluating cell cycle, mitochondrial membrane potential, caspase and ROS dependence for cell death, autophagosome formation, eIF2- $\alpha$ phosphorylation, DAMPs release and the role of autophagy in the mechanism of ICRP-induced cell death.

\section{Methods \\ Cell culture}

Human cervix adenocarcinoma HeLa $\left(\mathrm{ATCC}^{\circledR} \mathrm{CCL}^{\mathrm{m}}{ }^{\mathrm{m}}\right.$ ) and human breast adenocarcinoma MCF-7 (ATCC ${ }^{\circ}$ HTB-22 ${ }^{\mathrm{rm}}$ ) cells were obtained from the American Type Culture Collection (2015), mycoplasma tested (last test August 2019), and maintained in a humidified incubator containing $5 \% \mathrm{CO}_{2}$ at $37{ }^{\circ} \mathrm{C}$. Cells were cultured in DMEM-F12 supplemented with $10 \%$ fetal bovine serum (FBS) and 1\% penicillin-streptomycin (Life Technologies, Grand Island, NY), and were routinely grown in plastic tissue-culture dishes (Life Sciences, Corning, NY).

Peripheral blood mononuclear cells (PBMC) extraction.

After obtaining written informed consent, PBMC were isolated from healthy donors by density gradient centrifugation with Ficoll-Paque ${ }^{\mathrm{Tm}}$ PLUS (GE Healthcare, Chicago, Ilinois, USA) and maintained at $4 \times 10^{6}$ cells/ $\mathrm{mL}$ in cell culture plates at $37^{\circ} \mathrm{C}$ in $5 \% \mathrm{CO}_{2}$ atmosphere, using RPMI 1640 medium (GIBCO Thermofisher, Waltham, Massachusetts, USA) supplemented with $1 \mu \mathrm{g} /$ $\mathrm{mL}$ amphotericin $\mathrm{B}, 1 \mu \mathrm{g} / \mathrm{mL}$ penicillin and $2.5 \times 10^{-3}$ $\mu \mathrm{g} / \mathrm{mL}$ streptomycin (GIBCO Thermofisher, Waltham, Massachusetts, USA) and 10\% of FBS (GIBCO Thermofisher, Waltham, Massachusetts, USA). The study was approved by the Institutional Ethics Committee at the Universidad Autonoma de Nuevo León, College of Biological Sciences.

\section{Cell death analysis}

Cell death was determined by staining cells with $2.5 \mu \mathrm{g} /$ $\mathrm{mL}$ APC Annexin V (BD Pharmingen, San Jose, CA) and $0.5 \mu \mathrm{g} / \mathrm{mL}$ propidium iodide (PI) (Sigma-Aldrich, ST. Louis, MO). In brief, $5 \times 10^{4}$ cells were seeded in 24well plates and were incubated with IMMUNEPOTENT CRP for $24 \mathrm{~h}$, with or without pre-incubation with QVD.oph $(10 \mu \mathrm{M}), \mathrm{N}$-acetyl-L-cysteine (NAC) $(5 \mathrm{mM})$ or Spautin-1 (Sp-1) $(15 \mu \mathrm{M})$. Cells were then recuperated, washed with PBS (Phosphate-buffered saline) and then resuspended in $100 \mu \mathrm{l}$ of binding buffer $(10 \mathrm{mM}$ HEPES/ $\mathrm{NaOH}$ pH 7.4, $140 \mathrm{mM} \mathrm{NaCl}, 2.5 \mathrm{mM} \mathrm{CaCl}_{2}$ ). Finally, cells were stained, incubated at $4{ }^{\circ} \mathrm{C}$ for $20 \mathrm{~min}$ and assessed with BD Accury C6 flow cytometer (Becton Dickinson, Franklin Lakes, NJ). The results were analyzed using FlowJo Software (LLC, Ashland, OR). 


\section{Mitochondrial membrane potential analysis}

Mitochondrial membrane potential was measured using $500 \mathrm{nM}$ TMRE (Sigma-Aldrich, ST. Louis, MO). In brief, $5 \times 10^{4}$ cells in 24-well dishes were incubated with or without IMMUNEPOTENT CRP $\left(\mathrm{CC}_{50}\right)$ for $24 \mathrm{~h}$. Cells were then recuperated, washed with PBS, stained, incubated at $37^{\circ} \mathrm{C}$ for $30 \mathrm{~min}$, and measured by flow cytometry as described above.

\section{ROS production analysis}

ROS generation was measured using $2.5 \mu \mathrm{M}$ DCFDA (Thermo Fisher Scientific, Waltham, MA). In brief, $5 \times$ $10^{4}$ cells in 24-well dishes were incubated with IMMUNEPOTENT CRP $\left(\mathrm{CC}_{50}\right)$ for $24 \mathrm{~h}$, with or without preincubation with NAC. Cells were then recuperated, washed with PBS, stained, incubated at $37^{\circ} \mathrm{C}$ for $30 \mathrm{~min}$, and measured by flow cytometry as mention.

\section{Cell cycle analysis}

Cell cycle distributions were determined by PI (SigmaAldrich, ST. Louis, MO) staining. $2 \times 10^{5}$ cells in 6-well dishes were incubated with ICRP for $24 \mathrm{~h}$. Cells were then washed with PBS and fixed in 70\% ethanol. Cells were washed with PBS, then incubated with $50 \mu \mathrm{g} / \mathrm{mL}$ PI and simultaneous $50 \mu \mathrm{g} / \mathrm{mL}$ RNase (Sigma-Aldrich, ST. Louis, MO) treatment at $37^{\circ} \mathrm{C}$ for $30 \mathrm{~min}$. Cell DNA contents were measured by flow cytometry as explained above.

\section{elF2a phosphorylation analysis}

For this assay, $2 \times 10^{5}$ cells were plated in 12-well dishes and were incubated with ICRP for $18 \mathrm{~h}$. Cell were collected and fixed (eBioscience ${ }^{\mathrm{Ts}}$ Foxp3 / Transcription Factor Fixation/Permeabilization) for $1 \mathrm{~h}$ at $4{ }^{\circ} \mathrm{C}$, washed with 2\%-FACS Buffer (PBS 1x and 2\% FBS), centrifuged twice at $2000 \mathrm{rpm}$ during $20 \mathrm{~min}$, suspended in $10 \%$ FACS Buffer (PBS 1x and 10\% FBS) and incubated for $30 \mathrm{~min}$ in shaken. Then, anti-EIF2S1 (phospho S51) antibody [E90] (Abcam, ab32157) (1:100) was added and incubated for $2 \mathrm{~h}$ and washed twice. Next, goat antirabbit IgG H\&L (Alexa Fluor ${ }^{\bullet} 488$ ) (Abcam, ab150077) (1:200) was added and incubated for $1 \mathrm{~h}$ in darkness. Finally, cells were washed and eIF2 $\alpha$ phosphorylation was measured by flow cytometry as described above.

For confocal microscopy $1.5 \times 10^{5}$ cells were planted on cover slides into 12-well dishes, treated with ICRP $\left(C_{50}\right)$ and incubated for $24 \mathrm{~h}$. Then, cells were washed and fixed with 4\% PFA, washed and permeabilized with $0.1 \%$ Triton Buffer, washed twice with $2 \%$ FACS buffer, and $10 \%$-FACS buffer was added and incubated during $45 \mathrm{~min}$. Next, recombinant anti-EIF2S1 (phospho S51) antibody [E90] (Abcam, ab32157) (1:250) was added, incubated for $2 \mathrm{~h}$ and washed thrice. Finally, goat antirabbit IgG H\&L (Alexa Fluor ${ }^{\ominus} 488$ ) (Abcam, ab150077)
(1:100) was added, incubated for $30 \mathrm{~min}$ in darkness, washed twice and assessed by confocal microscopy (Olympus X70).

\section{Calreticulin exposure}

For this evaluation, $1 \times 10^{6}$ cells were plated, left untreated or treated with ICRP, and incubated for $24 \mathrm{~h}$. Cells were harvested, washed, and stained with Calreticulin-Phycoerythrin (Calreticulin-PE, FMC-75; Enzo Life Science, Farmingdale, NY) antibody (1:1000) in 2\%-FACS buffer. After $1 \mathrm{~h}$ in darkness at room temperature $(\mathrm{RT})$, cells were washed and suspended in 100 microliters uL of $2 \%$-FACS buffer to be assessed by flow cytometry as mention before.

For confocal microscopy, $2.5 \times 10^{5}$ cells were plated, and then left untreated (control) or treated with ICRP $\left(\mathrm{CC}_{50}\right)$ and incubated for $24 \mathrm{~h}$. Then, cells were washed with PBS, stained with Calreticulin-PE antibody $(2 \mu \mathrm{g} /$ $\mathrm{mL}$ ) (Enzo Life Science, Farmingdale, NY) and incubated for $1 \mathrm{~h}$ in FACS buffer. Finally, cells were washed twice with PBS and assessed by confocal microscopy (Olympus $\mathrm{X} 70)$.

\section{ATP release assay}

For this, $1 \times 10^{6}$ cells $/ \mathrm{mL}$ were treated with ICRP for 24 h. Supernatants were used to assess extracellular ATP by a luciferase assay (ENLITEN kit, Promega, Madison, WI) following the manufacturer's instructions. Bioluminescence was assessed in the Synergy HT microplate reader using the Software Gen5 (BioTek, Winooski, VT) at 560 nm.

\section{High-mobility group box 1 release assay}

Supernatants of untreated and ICRP-treated cells $(1 \times$ $10^{6}$ cells $/ \mathrm{mL}$ ) were used to measure extracellular HMGB1 using an HMGB1 ELISA kit (BioAssay ELISA kit human; US Biological Life Science, Salem, MA), following the manufacturer's instructions. Absorbance was assessed in the Synergy HT microplate reader using the Software Gen5 (BioTek, Winooski, VT) at $450 \mathrm{~nm}$.

\section{Cell morphology assessment}

HeLa and MCF-7 cells were cultured in 24-well plates and left untreated or incubated for $24 \mathrm{~h}$ with ICRP, with or without pre-incubation with NAC (20 min). After the incubation time, cells were observed in an inverted microscope (NIKON TS100) and pictures were obtained with an Infinity1 (Lumera) camera (10X).

\section{Autophagosome formation analysis}

For this assay, $5 \times 10^{4}$ cells were cultured in 24-well plates (Life Sciences) and left untreated or incubated for $24 \mathrm{~h}$ with ICRP, with or without pre-incubation with Sp1 or NAC. Then, cells were recuperated, washed with 
PBS, stained with CYTO-ID Autophagy Detection Kit (Enzo Life Science, Farmingdale, NY) and measured by flow cytometry as explained above.

\section{Statistical analysis}

The results presented here represent the mean of at least three independent experiments done in triplicate (mean $\pm \mathrm{SD}$ ). Statistical analysis was done using paired student $\mathrm{T}$-test, and the statistical significance was defined as $p<0.05$. The data was analyzed using GraphPad Prism (GraphPad Software, San Diego, CA, USA).

\section{Results}

IMMUNEPOTENT CRP induces cell death in HeLa and MCF-7 cells through cell cycle arrest, loss of mitochondrial membrane potential and ROS generation ICRP induces regulated cell death in $\mathrm{HeLa}, \mathrm{SiHa}$, A549 and A427 cells [2,3], while sparing noncancerous cells [6], however its effect on breast cancer derived-MCF-7 cell line, has not been assessed. Thus, to determine the effect of ICRP in MCF-7 cells, we evaluated cell death induced by different doses of ICRP after $24 \mathrm{~h}$ of treatment using HeLa cells and healthy-donor derived PBMC as a control. ICRP induced cell death in a concentrationdependent manner, in both cell lines, after $24 \mathrm{~h}$ of treatment (Fig. 1a), while PBMC were only slightly affected. Cell death was characterized by double-positive Annexin-V and PI staining, as previously reported for cervical cancer [3] and lung cancer cells [2]. In HeLa cells, ICRP provoked cell death (Annexin-V and/or PI staining) in $30 \%$ of the cells at $1 \mathrm{U} / \mathrm{mL}$ dose, reaching $50 \%$ at $1.25 \mathrm{U} / \mathrm{mL}$ and increasing near to $90 \%$ at $1.5 \mathrm{U} /$ $\mathrm{mL}$. In MCF-7 cells, ICRP induced a slight cell death at $1.25 \mathrm{U} / \mathrm{mL}$ (less than $20 \%$ of the cells), and at $1.5 \mathrm{U} / \mathrm{mL}$ it induced cell death in $50 \%$ of the cells, reaching $80 \%$ at $1.75 \mathrm{U} / \mathrm{mL}$. On the other hand, ICRP induced a slight cell death induction at $1.25 \mathrm{U} / \mathrm{mL}$ and at $1.5 \mathrm{U} / \mathrm{mL}$ (less than $20 \%$ of the cells), reaching $20 \%$ of cell death at 1.75 $\mathrm{U} / \mathrm{mL}$ in PBMC (Fig. 1a).

Moreover, it is known that mitochondria play a central role in cell death signaling, as mitochondrial dysfunction leads to ROS generation which has been associated with many types of cell death [16]. Thus, loss of mitochondrial membrane potential and ROS production were evaluated in HeLa, MCF-7, and PBMC after ICRP CC 50 treatment for $24 \mathrm{~h}$. As expected, loss of mitochondrial membrane potential (Fig. 1b) and ROS generation (Fig. 1c) were observed in 50\% of the HeLa and MCF-7 cells after treatment in both cell lines, whereas in PBMC we could observe a slight and non-significant loss of mitochondrial membrane potential (Fig. 1b) and ROS production (Fig. 1c). Because we observed that ICRP did not generate a significant affectation in PBMC, further studies were continued using only HeLa and MCF-7 cell lines.

ICRP is known to induce cell cycle arrest in HeLa cells in a time-dependent manner, reaching the maximum accumulation of cells in G2/M phase after $24 \mathrm{~h}$ of treatment [3]. Here we evaluated the cell cycle of MCF-7 cells after the treatment with ICRP using HeLa cells as a control. As seen in Fig. 1d and e, ICRP effectively induces cell cycle arrest in the G2/M phase in both cell lines after $24 \mathrm{~h}$ of treatment. Additionally, ICRP also induces cell cycle arrest in S phase in MCF-7 cells (Fig. 1d, e).

\section{IMMUNEPOTENT CRP induces caspase-independent cell death but in a ROS-dependent manner in HeLa and MCF- 7 cells}

Once we confirmed that the principal cell death features induced by ICRP in HeLa cells were maintained in breast cancer cells, we next wondered if the cell death was also caspase-independent, as previously shown in HeLa cells [3]. To determine this, a pan-caspase inhibitor, QVD.oph, was used before treatment with ICRP. As shown in Fig. 2a, ICRP-mediated cell death was independent of caspase activation in HeLa and MCF-7 cells.

Then, as ROS generation has been associated with caspase-independent types of cell death [17], the antioxidant NAC was used to determine if ROS were playing a role in ICRP-induced cell death. NAC was able to inhibit ICRP-mediated cell death (Fig. 2b) by reducing ROS production in both cell lines (Fig. 2c).

\section{IMMUNEPOTENT CRP induces elF2 $a$ phosphorylation and DAMPS release in HeLa and MCF-7 cells}

Recently, our research group found that ICRP induced the release of several DAMPs (CRT, ATP, HSP70, HSP90 and HMGB1), and ICD in B16F10 murine melanoma cells [9]. However, these features have not been assessed in human cancer cells. Considering that one of the first steps in the induction of ICD is the activation of an ER stress response, which involves the phosphorylation of eIF2 $\alpha$ (P-eIF2 $\alpha)$ [11]; this parameter was evaluated in human cancer cell lines by flow cytometry after $18 \mathrm{~h}$ of treatment. As shown in Fig. 3a and b, ICRP was able to induce eIF2 $\alpha$ phosphorylation in 47 and $57 \%$ of HeLa and MCF-7 cells treated with ICRP, respectively; this was confirmed by confocal microscopy (Fig. 3c and Fig. 3d). Because DAMPs exposure and release has been implicated in cell death involving ER stress [10], the next step was to evaluate if treatment with ICRP could induce the exposure or release of the principal DAMPs in the human cancer cell lines HeLa and MCF-7.

First, CRT exposure was assessed by flow cytometry and the results showed that $50 \%$ of HeLa (Fig. 3e) and MCF-7 (Fig. 3f) cells treated with ICRP exposed CRT, 


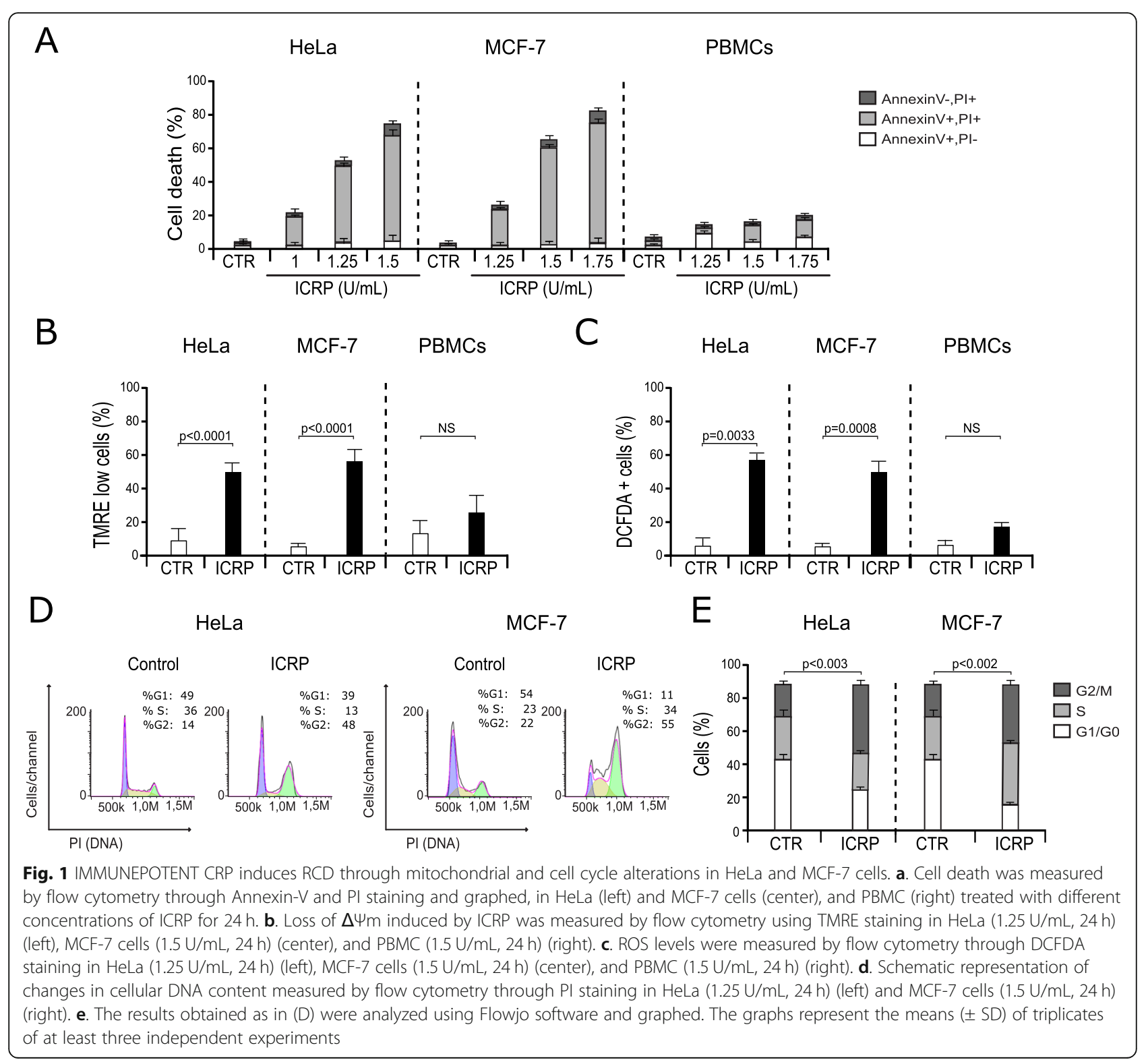

which was confirmed by confocal microscopy (Fig. 3g and Fig. 3h). Furthermore, as observed in Fig. 4, ICRP induced 393- and 114-fold ATP release, and 2.7- and 2.4-fold HMBG1 release in HeLa and MCF-7 cells, respectively, as compared with untreated control. These results indicate that ICRP induces ER stress and DAMPs release in cervical and breast cancer cell lines.

\section{IMMUNEPOTENT CRP induces ROS-dependent} autophagosome formation in HeLa and MCF-7 cells

ROS production and autophagosome formation have been related with the release of DAMPs. For this reason, evaluation of both characteristics was assessed in cervical and breast cancer cell lines. Morphological assessment of cells treated with ICRP indicated the presences of vacuoles in HeLa (Fig. 5a) and MCF-7 (Fig. 5b) cells. Additionally, intracellular formation of vacuoles depended of ROS production in cells treated with ICRP (Fig. 5a and Fig. 5b), thus, the next step was to evaluate if autophagy was taking place after ICRP treatment and if this was dependent of ROS production. We demonstrated that ICRP effectively induced autophagosome formation in approximately $40 \%$ of Hela (Fig. 5c) and $50 \%$ of MCF-7 (Fig. 5d) cells. Furthermore, autophagosome formation was ROS-dependent, as the use of the antioxidant NAC completely inhibits autophagosomes in cells treated with ICRP (Fig. 5c-e). 




IMMUNEPOTENT CRP induces pro-survival autophagosomes in HeLa and MCF-7 cells

Autophagy can be pro-survival or pro-death [18]. Indeed, there is a type of regulated cell death that relies on the autophagic machinery (or components) called "autophagic cell death" which is characterized by being caspase-independent [14, 17]. We observed autophagosome formation and caspase-independent cell death after ICRP treatment in HeLa and MCF-7 cells, the next question was whether the mechanism of death induced by ICRP relied on autophagy. Therefore, the autophagic inhibitor Spautin-1 (SP-1) was used to analyze if autophagosome formation was pro-survival or pro-death. For this purpose, autophagosome formation was assessed with or without SP-1 pre-treatment. In Fig. 6, SP-1 was able to completely inhibit autophagosome formation in HeLa (Fig. 6a) and MCF-7 cells (Fig. 6b). Then, the role of autophagosomes in the cell death induced by ICRP was evaluated. Results show that cell death was not inhibited with SP-1 (Fig. 6c), furthermore, cell death significatively augmented when autophagy was inhibited. Through these results we can conclude that ICRP induces pro-survival autophagosome formation in both cell lines.

\section{Discussion}

Cancer is a heterogeneous disease, and one of the challenges of cancer treatment is that each type of cancer has different molecular features. Here, we use two different cell lines, human cervix adenocarcinoma HeLa and human breast adenocarcinoma MCF-7 cells, and show that ICRP induces cell death, loss of mitochondrial membrane potential, ROS production and cell cycle arrest. Both cell lines exhibit the same mechanism, that is to say, a type of caspase-independent cell death that relies on ROS production. The observation of a conserved cell death mechanism in both cell lines has been reported in studies with other agents. For instance, Khazaei et al. demonstrated that broadleaf wild leek (Allium atroviolaceum) bulb extract induces cell death in HeLa and MCF-7 cells, sharing some features of the cell death mechanism induced by this treatment, such as Bcl-2 downregulation, DNA degradation and caspase activation on both cell lines [19]. On the other hand, Martinez-Torres et al., found that chitosan gold nanoparticles ( $\mathrm{CH}$-AuNPs) induce cell death in HeLa and MCF-7 cells though different cell death mechanisms. In HeLa cells they observed that the cell death induced by $\mathrm{CH}$-AuNPs was dependent of caspase activation, whereas it was caspase independent in MCF-7 cells. 


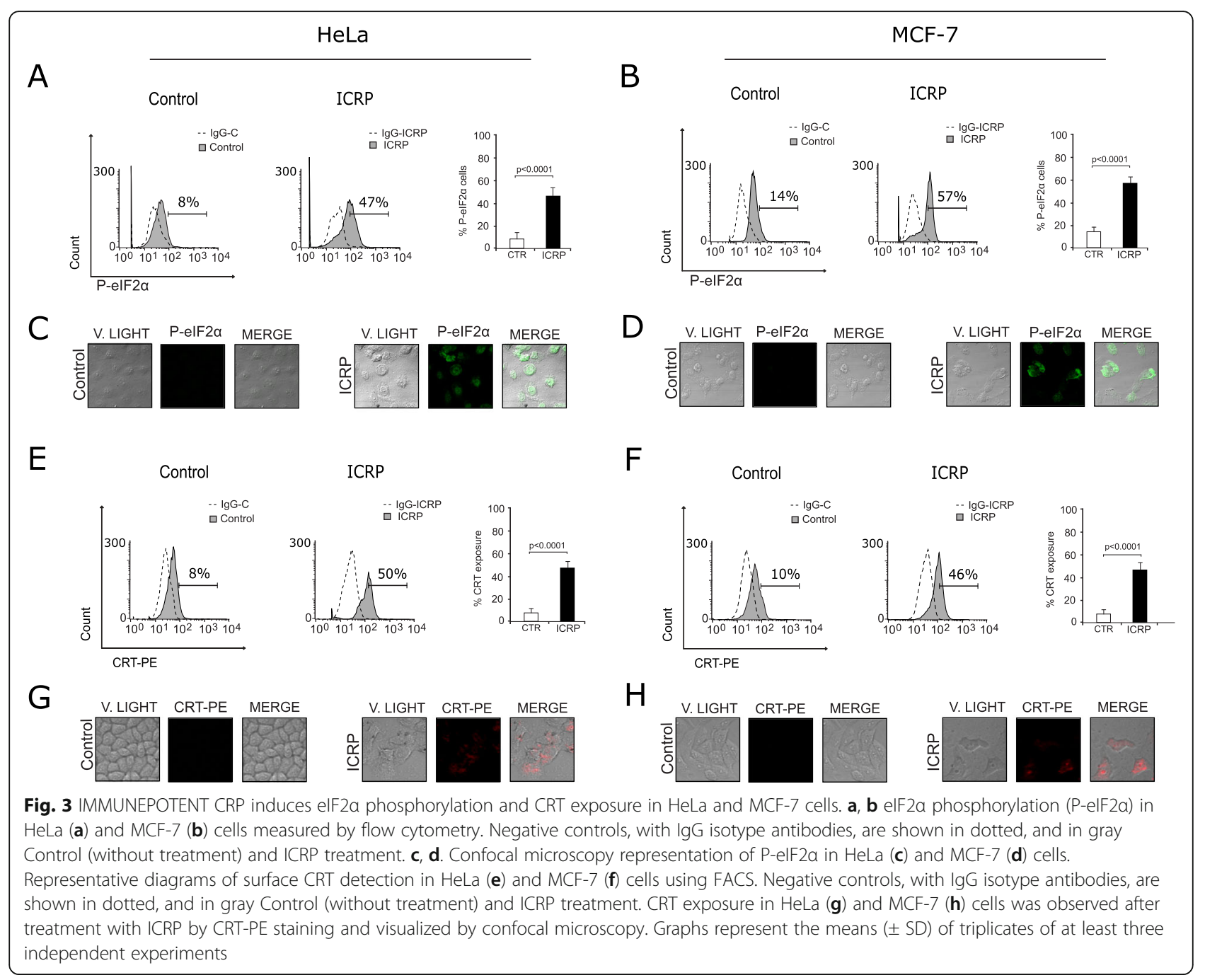

A

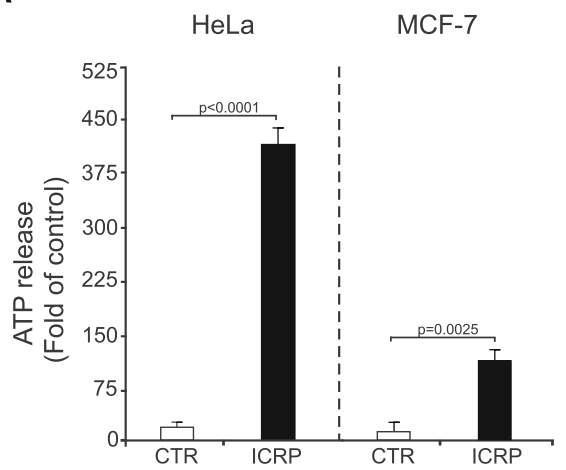

B

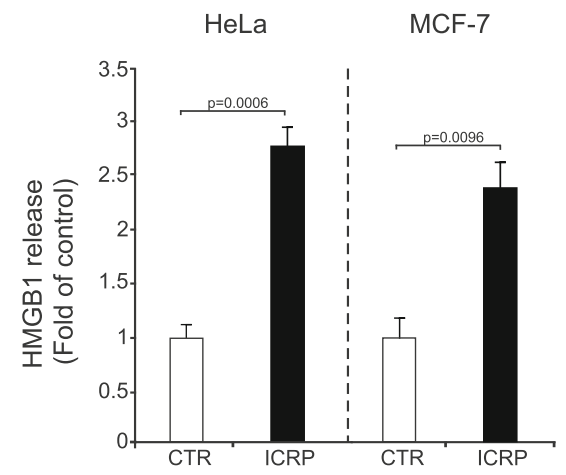

Fig. 4 IMMUNEPOTENT CRP induces ATP and HMGB1 release in HeLa and MCF-7 cells. Cells were treated with ICRP (HeLa: 1.25 U/mL; MCF-7: 1.5 $\mathrm{U} / \mathrm{mL}$ ) for $24 \mathrm{~h}$, then $100 \mu \mathrm{L}$ supernatant of each sample was taken to measure $\mathbf{a}$. ATP release through bioluminescence detection or $\mathbf{b}$. HMGB1 release by ELISA. Graphs shown are means $( \pm S D$ ) of triplicates of three independent experiments 


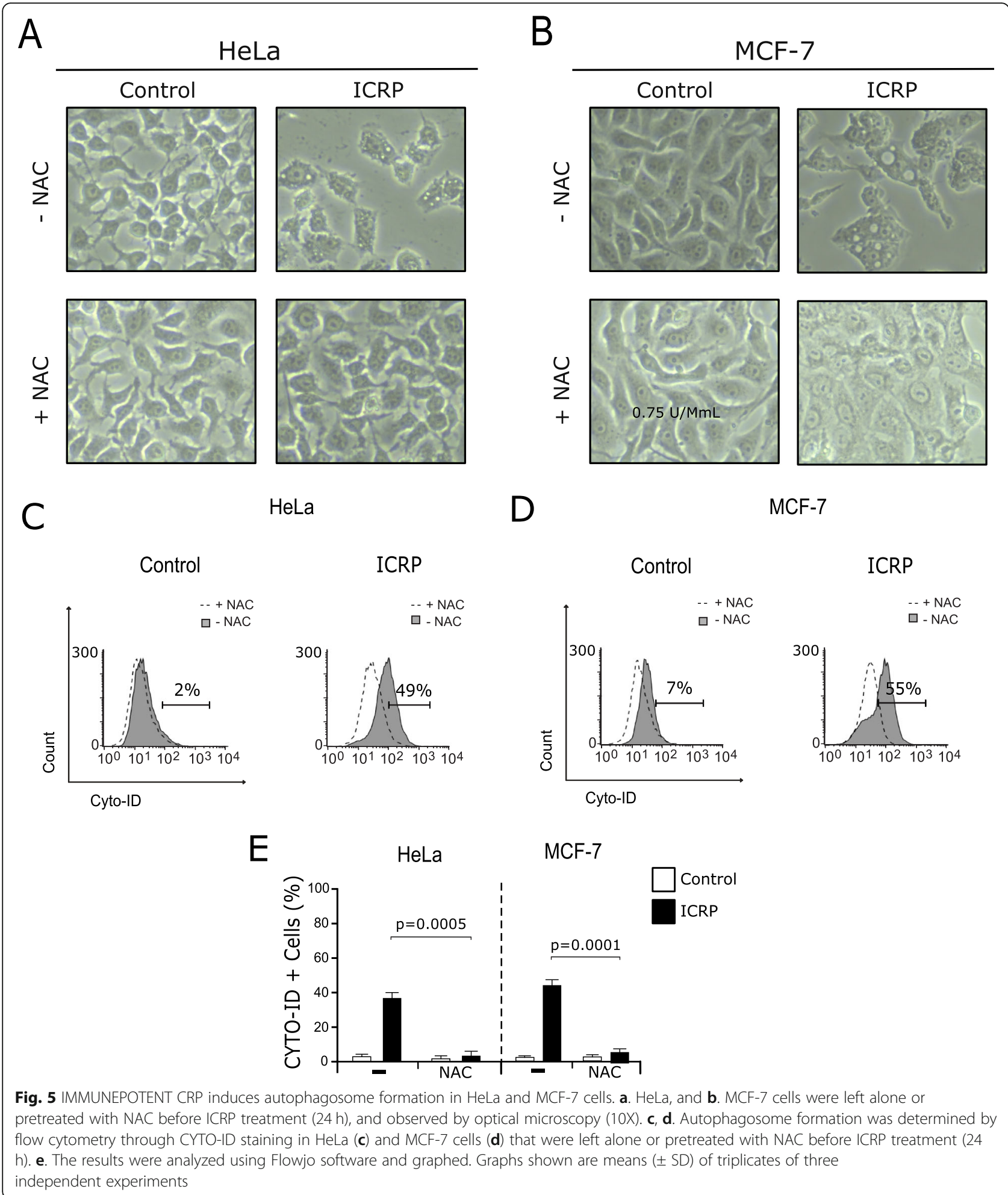

However, they also proved that ROS production seems to be a conserved feature of the cell death mechanism induced by $\mathrm{CH}$-AuNPs [20]. In another study, Green tea polyphenols (GTP) were evaluated in vitro in different cell lines, where they found that MCF-7 cells where more sensitive to the treatment with GTP than HeLa cells [21]. These variable mechanisms observed in HeLa and MCF-7 cells rely on the similarities and differences between the molecular machinery existing on each cell line. Here, we have proved that ICRP could induce a 


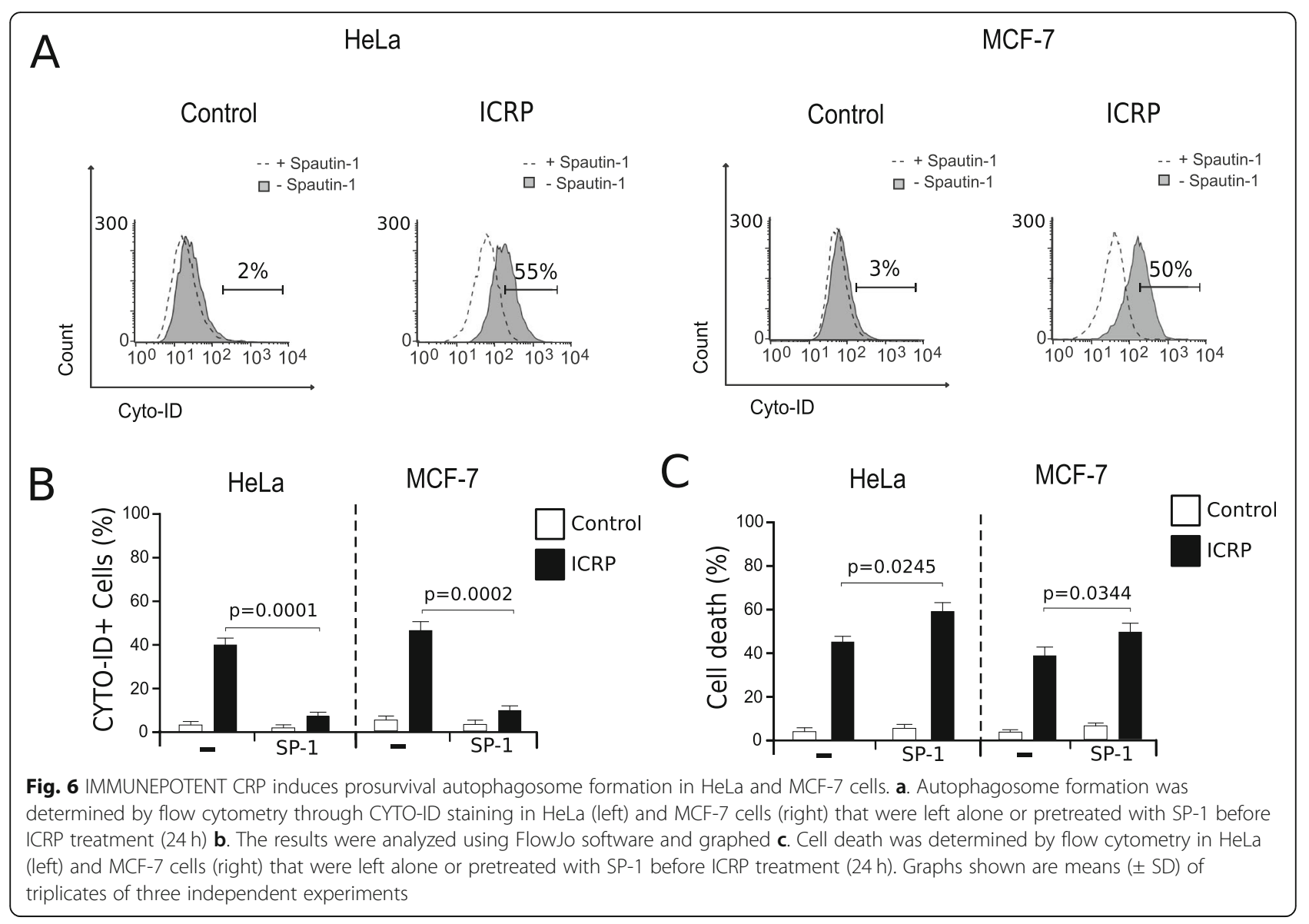

conserved mechanism of cell death in these two cell lines, as observed before in non-small cell lung cancer cell lines (A549 and A427 cells) where ICRP induced DNA degradation, mitochondrial damage, ROS production, and cell death independent of caspases but reliant on ROS production [2]. This indicates that the treatment with ICRP can overcome the mechanisms of cell death resistance existing in different types of cancer cells. However, it is important to mention, that differences in the cell death mechanism induced by ICRP in HeLa and MCF-7 cells could be observed in further analyses.

There is still much to understand about the mechanisms by which ICRP exerts these effects, nevertheless, in this work, we have shown that the cytotoxic effect induced by ICRP in HeLa and MCF-7 cells relies on the increase of ROS production. Interestingly, in our previous work, we observed that, in HeLa cells, the increase of ROS formation is one of the first steps of cell death induced by ICRP, even before caspase activation [3]. This ROS-dependent cell death has been induced by other treatments. For example, Wu et al. demonstrated that the protein kinase $C$ inhibitor, Chelerythrine, could induce cell death through ROS-dependent ER stress in human prostate cancer cells [22]. Furthermore, Kim et al. observed that Resveratrol-induced cell death in ovarian cancer cells was attenuated by the antioxidant NAC, and there was a ROS-dependent decrease of Notch1 signaling on these cells after treatment [23]. However, despite the implication of ROS in cell death, there are some agents that induce cell death without relying in ROS production [24-26].

Additionally, ROS production has been related with the induction of ICD, considering that DAMPs release is either accompanied or triggered by ROS [27]. Recently, our research group found that ICRP induces ICD in a murine melanoma model [9]. Here, we observed that ICRP induces the exposure and release of the principal DAMPs (CRT, ATP and HMBGB1) and eIF2 $\alpha$ phosphorylation, a process known as an ER stress indicator and biomarker of ICD [11], in the human cancer cells, HeLa and MCF-7 cells, indicating that ICRP could induce ICD in these models. Caspase-independent ICD has been observed in studies with other treatments, for instance, the CD47-agonist peptide PKHB1-induced caspase-independent and $\mathrm{Ca}^{2+}$-dependent cell death, pursing an immunogenic mechanism of cell death in leukemic cells [28, 29]; in addition, Giampazolias et al. demonstrated that in contrast to apoptosis, cells 
undergoing caspase-independent cell death generated a pro-inflammatory and immunogenic anti-tumour response through the activation of nuclear factor- $\mathrm{k} B$ (NF-kB) [30].

Furthermore, recent studies argue that ROS and other reactive species are the main intracellular signal transducers sustaining autophagy, because the ROS scavenger NAC attenuated induced autophagy by citreoviridin [31], hydroxysafflor yellow A-sonodynamic therapy [32], ergosterol peroxide from marine fungus Phoma sp. [33], patulin [34], dimethylaminomicheliolide [35] and many other agents. In this work, we proved that ICRP induces ROS-dependent autophagosome formation in both cell lines. This ROS-Autophagy interplay has been related with the induction of ICD as well, because these processes can play a central role in the exposure and release of DAMPs [12]. ROS production, autophagosome formation, DAMPs release and ER stress have been observed in the induction of ICD by other treatments, including mitoxantrone, doxorubicin, oxaliplatin and photodynamic therapy [10, 27, 36-38]. However, it will be necessary to perform gold-standard vaccination experiments to determine whether ICRP is a bona fide ICD inducer in these cancer models [39].

Moreover, autophagy has been referred to as a doubleedge sword because it helps maintain cell homeostasis but, in certain contexts, excessive or sustained cell autophagy may be pro-death [18]. Furthermore, autophagy may not be necessary for the induction of cell death but may be required for its immunogenicity [40], thus, we evaluated the role of autophagosome formation in the mechanism of cell death induced by ICRP, finding that it induces prosurvival autophagosomes in HeLa and MCF-7 cells. This role of autophagy as a cancer cell's pro-survival response to therapeutics has been observed in many treatments, including trastuzumab [41], epiribicin [42], tamoxifen [43], paclitaxel [44] and radiation [45]. Thus, it will be important to evaluate the role of autophagy in the induction of DAMPs release by ICRP to have a better understanding of the mechanism of action of this treatment.

Here we demonstrate that ICRP is able to induce a selective non-apoptotic cell death that promotes ER-stress and DAMP's release. These characteristics shed light into the therapeutic potential of the combination of ICRP with traditional chemotherapies, which seems encouraging, as observed in murine melanoma where ICRP increased the immunogenicity of oxaliplatin treatment [9]. Additionally, in the $4 \mathrm{~T} 1$ murine model it was observed that ICRP improved the antitumor effects of doxorubicin/cyclophosphamide treatment [8]. Thus, further assessments to describe the cell death mechanism and the potential immunogenic mechanism of the combination of ICRP with classical chemotherapies will undoubtedly straighten its applicability and advantage against cervical and breast cancer.

\section{Conclusions}

Overall our results show that IMMUNEPOTENT CRP induces cell cycle arrest, mitochondrial damage, ROSdependent autophagosome formation with a pro-survival role, ER stress and DAMPs release, pursing a nonapoptotic cell death, relying on ROS production in HeLa and MCF-7 cells. These data postulate ICRP as a treatment that could execute a conserved mechanism of cell death, in spite of the heterogeneity of cancer cells, opening the gate to the study of the immunogenic potential of ICRP-induced cell death in cervical and breast cancer models.

\section{Abbreviations}

ICRP: IMMUNEPOTENT-CRP; ROS: Reactive oxygen species; RCD: Regulated Cell Death; Ann/PI: Annexin-V-Allocp/ Propidium iodide; ICD: Immunogenic cell death; ER: Endoplasmic Reticulum; DAMPs: Damage-associated molecular patterns

\section{Acknowledgements}

We are grateful to Alejandra Elizabeth Arreola-Triana for article revision and editorial support for this manuscript. We thank Luis Gómez-Morales, Alan B. Martinez-Loria, Helen Y. Lorenzo-Anota, and Milena Benitez-Londoño for preliminary data and technical help. We thank Longeveden, SA de CV and the Laboratorio de Inmunología y Virología from Facultad de Ciencias Biologicas of the Universidad Autonoma de Nuevo Leon for the funding and the facilities provided to achieve this work. ARR and KMCR thank CONACyT for scholarship.

\section{Authors' contributions \\ ACMT, ARR, KMCR, KMAV, ACUP, RSTG, and CRP analyzed and interpreted data. ACMT, ARR, KMCR, KMAV, ACUP, performed statistical analysis. ACMT conceived and designed the experiments, supervised work, and wrote the final manuscript. ARR carried out the cell viability, cell cycle, cell death analysis, caspase, and ROS assessment. KMCR and ARR prepared figures. KMAV autophagy experiments. ACMT, ARR, and KMCR draft the manuscript. All authors revised, read, and approved the final manuscript.}

Funding

This work was supported by the Laboratorio de Inmunología y Virología.

\section{Availability of data and materials}

The datasets used and/or analysed during the current study are available from the corresponding author on reasonable request.

\section{Ethics approval and consent to participate}

The study was approved by the Institutional Ethics Committee at the Universidad Autonoma de Nuevo León, College of Biological Sciences. The healthy blood donors provided a written informed consent agreeing to participate.

\section{Consent for publication \\ Not Applicable.}

\section{Competing interests}

The authors declare that they have no competing interests.

\section{Author details}

${ }^{1}$ Universidad Autonoma de Nuevo Leon, Facultad de Ciencias Biologicas, Laboratorio de Inmunologia y Virologia, San Nicolás de los Garza, Mexico. ${ }^{2}$ Longeveden, SA de CV, Monterrey, Mexico. 
Received: 30 December 2019 Accepted: 1 July 2020

\section{Published online: 13 July 2020}

\section{References}

1. Siegel RL, Miller KD, Jemal A. Cancer statistics, 2019. CA Cancer J Clin. Jan. 2019;69(1):7-34

2. Martinez-Torres AC, Gomez-Morales L, Martinez-Loria AB, UscangaPalomeque AC, Vazquez-Guillen JM, Rodriguez-Padilla C. Cytotoxic activity of IMMUNEPOTENT CRP against non-small cell lung cancer cell lines. PeerJ. 2019;2019(9)e7759:1-18.

3. Martínez-Torres AC, Reyes-Ruiz A, Benítez-Londoño M, Franco-Molina MA, Rodríguez-Padilla C. IMMUNEPOTENT CRP induces cell cycle arrest and caspase-independent regulated cell death in HeLa cells through reactive oxygen species production. BMC Cancer. 2018;18:13.

4. Franco-Molina MA, et al. In vitro effects of bovine dialyzable leukocyte extract (bDLE) in cancer cells. Cytotherapy. 2006;8(4):408-14.

5. Mendoza-Gamboa E, et al. Bovine dialyzable leukocyte extract modulates AP-1 DNA-binding activity and nuclear transcription factor expression in MCF-7 breast cancer cells. Cytotherapy. 2008;10(2):212-9.

6. Lorenzo-Anota HY, et al. Bovine dialyzable leukocyte extract IMMUNEPOTENT-CRP induces selective ROS-dependent apoptosis in T-acute lymphoblastic leukemia cell lines. J. Oncol. 2020;2020:1-17.

7. Franco-Molina MA, et al. Antiangiogenic and antitumor effects of IMMUNEPOTENT CRP in murine melanoma. Immunopharmacol Immunotoxicol. 2010;32(4):637-46.

8. Santana-Krímskaya SE, et al. IMMUNEPOTENT CRP plus doxorubicin/ cyclophosphamide chemotherapy remodel the tumor microenvironment in an air pouch triple-negative breast cancer murine model. Biomed Pharmacother. 2020;126:110062.

9. Rodríguez-Salazar MDC, et al. The novel immunomodulator IMMUNEPOTENT CRP combined with chemotherapy agent increased the rate of immunogenic cell death and prevented melanoma growth. Oncol Lett. 2017;14(1):844-52.

10. Krysko DV, Garg AD, Kaczmarek A, Krysko O, Agostinis P, Vandenabeele P. Immunogenic cell death and DAMPs in cancer therapy. Nature Reviews Cancer. 2012;12(12):860-75.

11. Kepp O, et al. EIF2a phosphorylation as a biomarker of immunogenic cell death. Seminars in Cancer Biol. 2015;33:86-92.

12. Hou W, et al. Strange attractors: DAMPs and autophagy link tumor cell death and immunity. Cell Death Dis. 2013;4(12):e966.

13. Zhang Q, Kang R, Zeh HJ, Lotze MT, Tang D. DAMPs and autophagy: Cellular adaptation to injury and unscheduled cell death. Autophagy. 2013; 9(4) Taylor and Francis Inc.:451-8.

14. Doherty J, Baehrecke EH. Life, death and autophagy. Nature Cell Biol. 2018; 20(10) Nature Publishing Group:1110-7.

15. Kroemer G, Galluzzi L, Kepp O, Zitvogel L. Immunogenic cell death in Cancer therapy. Annu Rev Immunol. 2013;31:51-72.

16. Vakifahmetoglu-Norberg $\mathrm{H}$, Ouchida AT, Norberg E. The role of mitochondria in metabolism and cell death. Biochem Biophys Res Communications. 2017:482(3) Elsevier B.V:426-31.

17. Galluzzi L, et al. Molecular mechanisms of cell death: Recommendations of the Nomenclature Committee on Cell Death 2018. Cell Death and Differentiation. 2018;25(3) Nature Publishing Group:486-541.

18. Das CK, Mandal M, Kögel D. Pro-survival autophagy and cancer cell resistance to therapy. Cancer Metastasis Rev. 2018;37(4) Springer New York LLC:749-66.

19. Khazaei $\mathrm{S}$, et al. In vitro antiproliferative and apoptosis inducing effect of Allium atroviolaceum bulb extract on breast, cervical, and liver cancer cells. Front. Pharmacol. 2017;8(JAN):5.

20. Martínez-Torres AC, Zarate-Triviño DG, Lorenzo-Anota HY, Ávila-Ávila A, Rodríguez-Abrego C, Rodríguez-Padilla C. Chitosan gold nanoparticles induce cell death in hela and MCF-7 cells through reactive oxygen species production. Int J Nanomedicine. 2018;13:3235-50.

21. Liu S m, Ou S y, Huang H h. Green tea polyphenols induce cell death in breast cancer MCF-7 cells through induction of cell cycle arrest and mitochondrial-mediated apoptosis. J Zhejiang Univ Sci B. 2017;18(2):89-98

22. Wu S, et al. Chelerythrine induced cell death through ROS-dependent ER stress in human prostate cancer cells. Onco Targets Ther. 2018;11:2593-601.

23. Kim TH, Park JH, Woo JS. Resveratrol induces cell death through ROSdependent downregulation of Notch1/PTEN/Akt signaling in ovarian cancer cells. Mol Med Rep. 2019;19(4):3353-60.
24. Conway GE, et al. Non-thermal atmospheric plasma induces ROSindependent cell death in U373MG glioma cells and augments the cytotoxicity of temozolomide. Br J Cancer. 2016;114(4):435-43.

25. Seong M, Lee DG. Reactive oxygen species-independent apoptotic pathway by gold nanoparticles in Candida albicans. Microbiol Res. 2018;207:33-40.

26. Wang $H$, Zhang $X$. ROS reduction does not decrease the anticancer efficacy of X-Ray in two breast cancer cell lines. Oxid Med Cell Longev. 2019;2019. Article ID 3782074:1-12.

27. Li X. The inducers of immunogenic cell death for tumor immunotherapy. Tumori. 2017;104(1) SAGE Publications Ltd:1-8.

28. Uscanga-Palomeque AC, et al. CD47 agonist peptide PKHB1 induces immunogenic cell death in T-cell acute lymphoblastic leukemia cells. Cancer Sci. 2019;110(1):256-68.

29. Martínez-Torres AC, et al. PKHB1 tumor cell lysate induces antitumor immune system stimulation and tumor regression in syngeneic mice with Tumoral T Lymphoblasts. J Oncol. 2019;2019:1-11.

30. Giampazolias E, et al. Mitochondrial permeabilization engages NF-kBdependent anti-tumour activity under caspase deficiency. Nat Cell Biol. Sep. 2017;19(9):1116-29.

31. Liu YN, et al. Citreoviridin induces ROS-dependent autophagic cell death in human liver HepG2 cells. Toxicon. Mar. 2015;95:30-7.

32. Jiang $Y$, et al. ROS-Dependent Activation of Autophagy through the PI3K Akt/mTOR Pathway Is Induced by Hydroxysafflor Yellow A-Sonodynamic Therapy in THP-1 Macrophages. Oxid Med Cell Longev. 2017;2017. Article ID 8519169:1-16.

33. Wu HY, et al. Ergosterol peroxide from marine fungus Phoma sp. induces ROS-dependent apoptosis and autophagy in human lung adenocarcinoma cells. Sci Rep. 2018;8(1):1-4.

34. Yang $G$, et al. Patulin induced ROS-dependent autophagic cell death in human Hepatoma G2 cells. Chem Biol Interact. 2018:288:24-31.

35. Wang $Y$, et al. ROS generation and autophagosome accumulation contribute to the DMAMCL-induced inhibition of glioma cell proliferation by regulating the ROS/MAPK signaling pathway and suppressing the Akt/ mTOR signaling pathway. Onco Targets Ther. 2019;12:1867-80.

36. Dudek AM, Garg AD, Krysko DV, De Ruysscher D, Agostinis P. Inducers of immunogenic cancer cell death. Cytokine Growth Factor Rev. 2013;24(4): 319-33.

37. Garg AD, et al. Molecular and translational classifications of DAMPs in immunogenic cell death. Front Immunol. 2015;6:588.

38. Rapoport BL, Anderson R. Realizing the clinical potential of immunogenic cell death in cancer chemotherapy and radiotherapy. Int J Mol Sci. 2019; 20(4):959 MDPI AG.

39. Kepp O, et al. Consensus guidelines for the detection of immunogenic cell death. Oncolmmunology. 2014;3(9):e955691.

40. Michaud $M$, et al. Autophagy-dependent anticancer immune responses induced by chemotherapeutic agents in mice. Science (80- ). 2011; 334(6062):1573-7.

41. Vazquez-Martin A, Oliveras-Ferraros C, Menendez JA. Autophagy facilitates the development of breast cancer resistance to the anti-HER2 monoclonal antibody trastuzumab. PLoS One. 2009;4(7):e6251.

42. Sun WL, Chen J, Wang YP, Zheng H. Autophagy protects breast cancer cells from epirubicin-induced apoptosis and facilitates epirubicin-resistance development. Autophagy. 2011;7(9):1035-44.

43. Qadir MA, et al. Macroautophagy inhibition sensitizes tamoxifen-resistant breast cancer cells and enhances mitochondrial depolarization. Breast Cancer Res Treat. 2008;112(3):389-403.

44. Wen J, et al. Autophagy inhibition re-sensitizes pulse stimulation-selected paclitaxel-resistant triple negative breast cancer cells to chemotherapyinduced apoptosis. Breast Cancer Res Treat. 2015;149(3):619-29.

45. Han MW, et al. Autophagy inhibition can overcome radioresistance in breast cancer cells through suppression of TAK1 activation. Anticancer Res. Mar. 2014;34(3):1449-55.

\section{Publisher's Note}

Springer Nature remains neutral with regard to jurisdictional claims in published maps and institutional affiliations. 